\title{
Chemical and pharmacological evaluation of the non-flowering aerial parts of Acacia modesta Wall. cultivated in Egypt
}

\author{
Eman Mohamed Salah" ${ }^{*}$ (D), Reham R. Ibrahim², Mariam H. Gonaid ${ }^{1}$ and Hesham S. M. Soliman²
}

\begin{abstract}
Background: Acacia modesta Wall. (A. modesta), often recognized as Phulai, is belonging to family Fabaceae and sub-family Mimosaceae. A. modesta has many beneficial uses. Leaves, wood, flowers, and gum of A. modesta have been used frequently for multiple therapeutic purposes.

Results: The chemical investigation of butanol fraction of A. modesta non-flowering aerial parts yielded Vitexin-2"- $\beta$ $D$-glucopyranoside and Apigenin-6,8-di-C- $\beta$-D-glucopyranoside in a flavone mixture as well as ( $\beta$-D-glucopyranosyl (1-3)- $\beta$-D-glucopyranosyl)-3- $\beta$-hydroxy-11-oxo-olean-12-en-28-oic acid) an oleanane-type triterpenoidal saponin. Metabolite profiling via ultra-performance liquid chromatography-electrospray ionization-mass spectrometry (UPLCESI-MS) of the ethyl acetate fraction resulted in recognizing of eighteen compounds tentatively compared with previously published data. Quantitative measurement of the overall value of flavonoids of A. modesta was found to be $2.824 \mu \mathrm{g} / 100 \mu \mathrm{g} \pm 0.01$ calculated as quercetin. The acute toxicity study of the ethanol extract proved that the plant under investigation is safe and nontoxic to the male albino mice used. The anti-hyperglycemic activity of the ethanol extract performed on type 2 diabetic rats proved that the most potent dosage was $200 \mathrm{mg} / \mathrm{kg} \mathrm{b}$. wt. after 4 and 4 weeks of treatment respectively compared to metformin. Furthermore, evaluation of the hepato-protective activity of the ethanol extract of the plant under investigation showed that the most potent extract was with a dose level of $200 \mathrm{mg} / \mathrm{kg}$ b. wt. after 3 and 10 days of continuous treatment compared to silymarin.
\end{abstract}

Conclusion: It can be concluded that A. modesta Wall. cultivated in Egypt could be used as a promising antidiabetic agent and a hepato-protective agent against hepatocellular damage induced by hepatotoxins.

Keywords: Acacia, Anti-hyperglycemic, Flavone, Hepato-protective, Saponin

\section{Background}

Traditional medicine is used globally and has significant economic benefits in both industrialized and developing economies using natural plants that are rich sources of active components, so knowledge about both the area's plant diversity and local people's medicinal uses is of utmost importance. Herbal plants play a key role in medicare and are therefore essential natural resources both for the traditional and innovative medicinal products [1].

\footnotetext{
* Correspondence: emanms4000@yahoo.com; eman.salah@fue.edu.eg ${ }^{1}$ Faculty of Pharmaceutical Sciences and Pharmaceutical Industries, Future University in Egypt, Cairo, Egypt

Full list of author information is available at the end of the article
}

Family Fabaceae is one of the fastest growing flowering plant families in the world, the third largest group of plants with 19,400 species, and has been categorized into 730 genera. Family Fabaceae plants supply a reliable and safe therapy for many diseases. Species of this family range from dwarf herbs to tropical rain forest massive trees [2]. Genus Acacia is a heterogeneous collection of ever more than 1000 species, most of which are trees, mainly found in Australia; others are found in SouthEast Asia [3]. Acacia species were first used in the beginnings of human civilization as traditional medicinal plants and have a really significant economic value [4]. Gum, leaves, flowers, and wood of $A$. modesta were used

\section{Springer Open}

(๑) The Author(s). 2020 Open Access This article is licensed under a Creative Commons Attribution 4.0 International License, which permits use, sharing, adaptation, distribution and reproduction in any medium or format, as long as you give appropriate credit to the original author(s) and the source, provide a link to the Creative Commons licence, and indicate if changes were made. The images or other third party material in this article are included in the article's Creative Commons licence, unless indicated otherwise in a credit line to the material. If material is not included in the article's Creative Commons licence and your intended use is not permitted by statutory regulation or exceeds the permitted use, you will need to obtain permission directly from the copyright holder. To view a copy of this licence, visit http://creativecommons.org/licenses/by/4.0/. 
for various medical applications such as dysentery, leprosy, and cough [5]. Different parts of A. modesta have been previously investigated in several pharmacological activities such as antibacterial, antifungal, antihyperglycemic, analgesic, anti-inflammatory, anti-platelet aggregation, anti-termite, antioxidant, brine shrimp cytotoxicity, hemagglutination, insecticidal, phytotoxic, and spasmolytic activities. Reports on $A$. modesta aerial parts exposed the presence of flavonoids, alkaloids, terpenoids, and tannins [6]. Tracing the available current literature, there is scarce information on the chemical and pharmacological characters of $A$. modesta cultivated in Egypt. Therefore, the following work has been planned to examine the main active principles and to screen the biological activities to find out the potential benefits of the plant under investigation.

\section{Methods}

\section{Collection of plant material}

The non-flowering aerial parts of $A$. modesta have been collected in August 2015 from Giza zoo garden, then identified and authenticated by the taxonomist Dr. Threse Labib, specialist in the central gardening administration, Orman garden, Giza, Egypt.

\section{Isolation and identification}

\section{Extraction of aerial parts of $A$. modesta}

About $500 \mathrm{~g}$ of the air-dried powdered non-flowering aerial parts of $A$. modesta have been exhaustively extracted with 70\% methanol, and filtered and then concentrated using rotary evaporator R-3 (Buchi, A.G., Switzerland). The crude extract $(100 \mathrm{~g})$ has been mixed with distilled water $(500 \mathrm{ml})$ and then has been partitioned with the following solvents; $n$-hexane, methylene chloride, ethyl acetate, and n-butanol saturated with water several times and concentrated to give $3 \mathrm{~g}, 3 \mathrm{~g}, 8 \mathrm{~g}$, and $17 \mathrm{~g}$, respectively. TLC profile of the $\mathrm{n}$-butanol fraction prompted to focus on its purification. The dried extract of the n-butanol fraction $(17 \mathrm{~g})$ was delivered over a silica gel (60) glass column and eluted with methylene chloride, and the polarity of the column was stepwise increased by gradient addition of methanol. Similar fractions of each $50 \mathrm{ml}$ were collected together. Fractions eluted with solvent strength (methylene chloride: methanol 70:30) offered fraction 1 (1.08 g) which was purified using reversed-phase silica column and partitioned with water, then increasing polarity via addition of methanol gradually. Similar fractions $(5 \mathrm{ml})$ each, eluted with (30\% methanol), were concentrated to offer compounds 1 and 2 (50 mg) (Supplementary file: Figures S1-S7). Similar fractions eluted from the main column using polarity (methylene chloride: methanol 60: 40) offered fraction 2 ( $1.37 \mathrm{~g}$ ) which has been separated via a sephadex LH-20 glass column, using absolute methanol to offer compound 3 (30 mg) (Supplementary file: Figures S8-S15).

\section{Materials for pharmacological screening Extract preparation}

Non-flowering A. modesta aerial parts have been left to dry in the air, and grinded and then extracted with absolute ethanol for hepato-protective and anti-diabetic activities. The extracts were dried using rotary evaporator R-3 (Buchi, A.G., Switzerland).

\section{Animals}

Adult male albino Sprague dawley rats (130-150 g) have been used for the hepato-protective and anti-diabetic activities. Mice $(25-30 \mathrm{~g})$ have been used for the toxicological study. Both have been brought from the animal house colony belonging to the National Research Centre, Dokki, Giza, Egypt. Experiments and animal procedures have been carried out in compliance with the Ethics Committee of the National Research Centre following the recommendations of the National Institutes of Health Guide for the Care and Use of Laboratory Animals. After each experiment, animals would be sacrificed by cervical dislocation via light anesthesia with ether.

\section{Quantitative estimation of flavonoid content}

A spectrophotometric method using aluminum chloride was followed for total flavonoid content estimation based on the measurement of the intensity of the color developed when flavonoids complexed with aluminum chloride, at $\lambda_{\max } 415 \mathrm{~nm}$ using the standard quercetin (Sigma-Aldrich chemicals, Co., St. Louis, MO, USA). The assay was done in triplicate. The calibration curve was prepared using quercetin solution at a concentration of 5 to $100 \mu \mathrm{g} / \mathrm{ml}$ in methanol [7].

\section{Metabolite profiling via UPLC-ESI-MS}

The sample solution of the ethyl acetate fraction of $A$. modesta $(100 \mu \mathrm{g} / \mathrm{mL})$ non-flowering aerial parts was prepared, the chromatographic separation was conducted on an Acquity UPLC system (Waters) equipped with a reversed-phase BEH C18 column $(50 \times 2.1 \mathrm{~mm}$, particle size $1.7 \mu \mathrm{m}$; Waters), and the analysis was carried out using a binary elution system. Mass spectra were detected between $\mathrm{m} / \mathrm{z} 100-1000$ in negative and positive ionization modes on a XEVO TQD triple quadrupole mass spectrometer (Waters Corporation, Milford, USA) [8]. Compounds were recognized tentatively by analyzing their mass data using the Maslynx 4.1 software and making a comparison between their retention time (RT) and mass spectrum with previously reported data. 


\section{Acute toxic activity}

A preliminary experiment was done to determine the minimal dose that kills all animals $\left(\mathrm{LD}_{100}\right)$ and the minimal dose that fails to kill any animal. Several doses at equal logarithmic intervals were chosen in between 2 doses; each dose was injected in a group of 10 animals by subcutaneous injection total of forty mice. The mice were then observed for $24 \mathrm{~h}$, and symptoms of toxicity and mortality rates were recorded and $L_{50}$ was calculated [9].

\section{Anti-hyperglycemic activity Induction of hyperglycemia}

Type 2 diabetes mellitus has been induced via alloxan injection [10]. Then, the measurement of the blood glucose levels was tested after $72 \mathrm{~h}$ to ensure hyperglycemia [11].

\section{Hepato-protective activity} Induction of liver damage

Liver damage has been ensured by injection of toxic carbon tetrachloride $\left(\mathrm{CCl}_{4}\right)$ dissolved via liquid paraffin
( $5 \mathrm{ml} / \mathrm{kg}$ of $25 \%$ ) via intra-peritoneal route, and blood samples were withdrawn for the biochemical study [12, 13]. Serum aspartate amino-transferase (AST), alanine amino-transferase (ALT) [14], and serum alkaline phosphatase (ALP) [15] were isolated and then analyzed. The data have been analyzed using Student's $t$ test [16].

\section{Results}

\section{Phytochemistry}

Phytochemical investigation of the butanol fraction of $A$. modesta non-flowering aerial parts has yielded three compounds. The chemical structures of the three compounds have been characterized using elemental analysis, ${ }^{1} \mathrm{H} \&{ }^{13} \mathrm{C}$ NMR correlating with the existing literature data [17].

\section{Vitexin-2"- $\beta$-glucopyranoside (compound 1)}

Brownish yellow amorphous powder, $R_{f}$ 0.53 (methylene chloride: methanol: distilled water 70:30:3). According to the chromatographic properties, this compound was expected to be an apigenin derivative [17] (Fig. 1).<smiles>O=c1cc(-c2ccc(O)cc2)oc2c(C3OC(CO)C(O)C(O)[C@H]3OC3OC(CO)[C+](O)[C-](O)C3O)c(O)cc(O)c12</smiles>

Vitexin-2"- $\beta$-glucopyranoside compound 1<smiles>O=c1cc(-c2ccc(O)cc2)oc2c(C3OC(CO)C(O)C(O)C3O)c(O)c(C3OC(CO)[C+](O)C(O)C3O)c(O)c12</smiles>

Apigenin-6,8-di- $C$ - $\beta$ - $D$-glucopyranoside (Vicenin II) compound 2

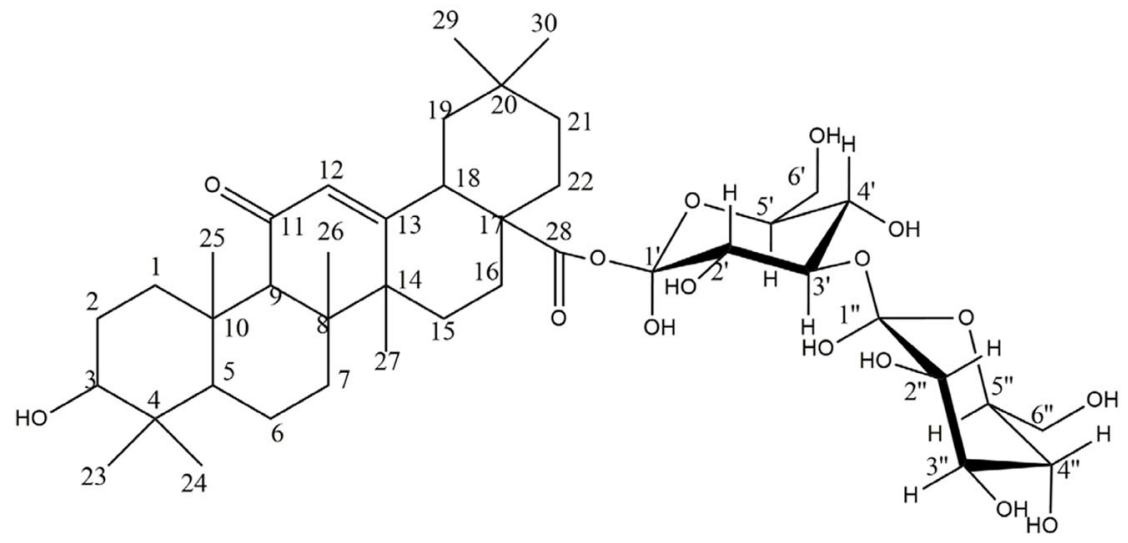

$\beta$-D-glucopyranosyl (1-3)- $\beta$ - $D$-glucopyranosyl)-3- $\beta$-hydroxy-11-oxo-olean-12-en-28-oic acid compound 3

Fig. 1 Isolated compounds of Acacia modesta Wall. non-flowering aerial parts. Figure 1 shows the three compounds isolated from the butanol fraction of A. modesta non-flowering aerial parts, compounds 1 and 2 were isolated in a flavone mixture, while compound 3 was isolated in a pure form 
Apigenin-6,8-di-C- $\beta$ - $D$-glucopyranoside (compound 2) Yellow amorphous powder, $R_{f}: 0.53$ (methylene chloride: methanol: distilled water 70:30:3) (Fig. 1).

\section{$\beta$-D-glucopyranosyl (1-3)- $\beta$ - $D$-glucopyranosyl)-3- $\beta$ -} hydroxy-11-oxo-Olean-12-en-28-oic acid (compound 3) Amorphous powder

It showed a positive test of Lieberman-Burchard test for terpenoid [18], $R_{f}: 0.8$ (methylene chloride: methanol: distilled water 70:30:3). The spectrum of ${ }^{13} \mathrm{C}$ NMR showed 30 carbon signals (Fig. 1).

\section{Quantitative estimation of flavonoid content}

The total flavonoid content of $A$. modesta Stock was found to be $2.824 \mu \mathrm{g} / 100 \mu \mathrm{g} \pm 0.01$ calculated as quercetin.

\section{UPLC-ESI-MS}

Tentative identification of the ethyl acetate fraction of $A$. modesta non-flowering aerial part metabolites has led to the identification of eighteen compounds which were distributed into two major categories: flavonoids and phenolic acids. The compounds were analyzed depending on their molecular weight, mass fragmentation, and compared with previously revealed data to the extent of our knowledge. It is important to mention that this is the first study for evaluating any fraction of $A$. modesta nonflowering aerial parts via UPLC-ESI-MS analysis (Fig. 2).

\section{Acute toxicity study $\left(\mathrm{LD}_{50}\right)$}

It was found that the median lethal dose of ethanol extract of $A$. modesta non-flowering aerial parts $\left(\mathrm{LD}_{50}\right)$ is $7.1 \mathrm{~g} / \mathrm{kg} \mathrm{b}$. wt., so it is possible to conclude that the $L D_{50}$ of alcoholic extract of $A$. modesta is safe and nontoxic as $\mathrm{LD}_{50}$ greater than $50 \mathrm{mg} / \mathrm{kg} \mathrm{b}$. wt. is nontoxic [19].

\section{Anti-hyperglycemic activity}

Results revealed that the ethanol extract of $A$. modesta showed a potent anti-diabetic activity at the two tested doses. From the examination of the two dose levels at $100 \mathrm{mg} / \mathrm{kg}$ b. wt. and at $200 \mathrm{mg} / \mathrm{kg}$ b. wt., respectively, of

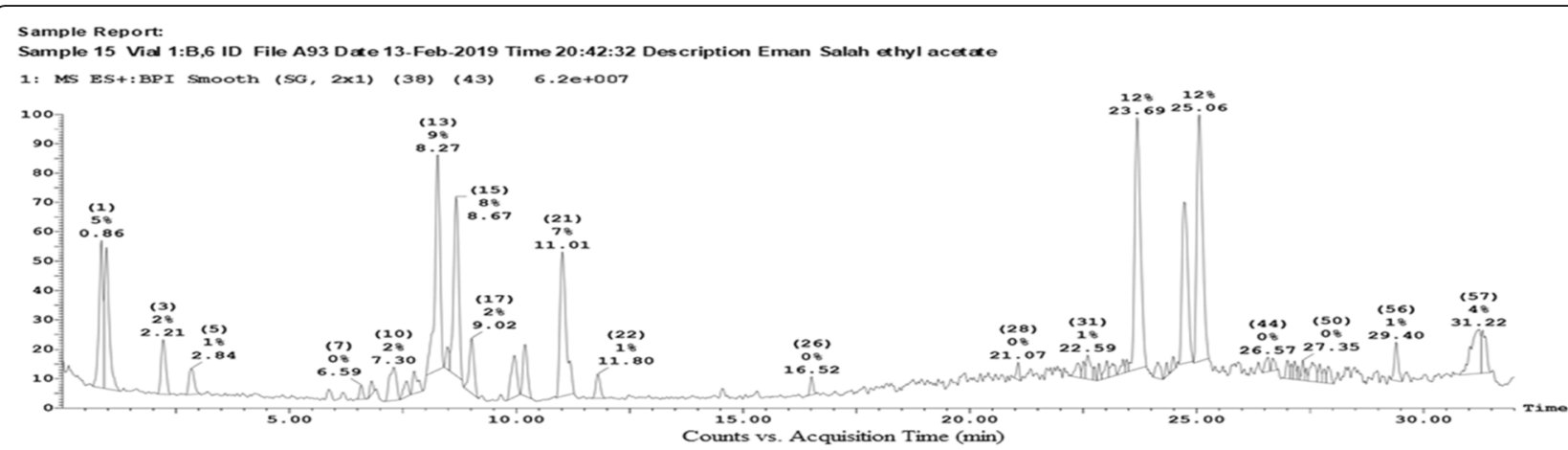

Total ion chromatogram (+ve ESI) $[\mathrm{M}+\mathrm{H}]^{+}$of the ethyl acetate fraction of Acacia modesta Wall.

Sample Report:

Sample 15 Vial 1:B,6 ID File A93 Date 13-Feb-2019 Time 20:42:32 Description Eman Salah ethyl acetate

2: MS ES-:BPI Smooth (SG, 2x1) (38) (43) $1.3 e+007$

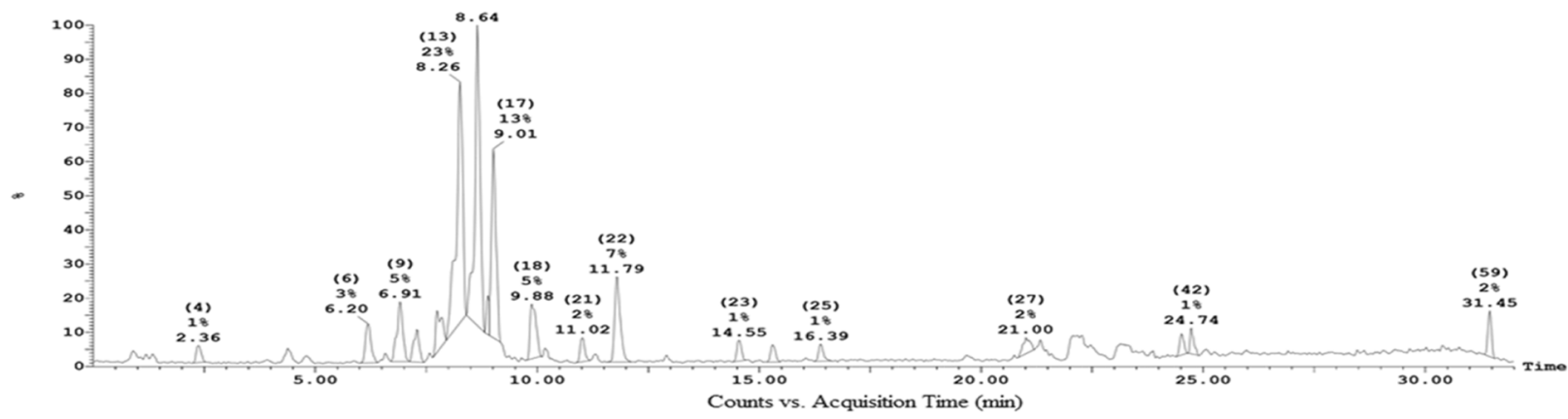

Total ion chromatogram (-ve ESI) [M-H] $]^{-}$of the ethyl acetate fraction of Acacia modesta Wall.

Fig. 2 UPLC-ESI-MS analysis of Acacia modesta Wall. non-flowering aerial parts. Figure 2 shows two chromatograms obtained by ultraperformance liquid chromatography-electrospray-mass spectrometry of the ethyl acetate fraction of $A$. modesta non-flowering aerial parts; the one from the left shows the total ion chromatogram at the positive mode and the chromatogram at the right shows the total ion chromatogram at the negative mode 
the ethanol extract of $A$. modesta non-flowering aerial parts cultivated in Egypt in AITD (Alloxan-induced type 2 diabetic rats) after 4 and 8 weeks of continuous treatment against standard anti-diabetic drug metformin with dose $100 \mathrm{mg} / \mathrm{kg}$ b. wt.: results showed a substantial decrease in blood glucose levels from $259.8 \mathrm{mg} / \mathrm{dl}$ in nontreated AITD to $209.1 \mathrm{mg} / \mathrm{dl}$ to $186.8 \mathrm{mg} / \mathrm{dl}$ in AITD treated with the two tested doses, respectively, compared with metformin $(143.6 \mathrm{mg} / \mathrm{dl})$. Furthermore, after 8 weeks of continuous treatment blood glucose levels was lowered from $268.4 \mathrm{mg} / \mathrm{dl}$ in non-treated AITD to 153.6 $\mathrm{mg} / \mathrm{dl}$ to $139.9 \mathrm{mg} / \mathrm{dl}$ in AITD treated with the two tested doses, respectively, compared with metformin $(85.4 \mathrm{mg} / \mathrm{dl})$ (Supplementary file: Table S1) (Fig. 3).

\section{Hepato-protective activity}

From the examination of the two doses 100 and $200 \mathrm{mg} /$ $\mathrm{kg}$ b. wt., respectively, of the ethanol extract of $A$. modesta non-flowering aerial parts cultivated in Egypt in comparison with silymarin as a standard hepatoprotective drug, blood samples were collected at zerotime, 1 week before $\mathrm{CCl}_{4}$ injection, 3 days, and then 10 days after $\mathrm{CCl}_{4}$ injection. Results showed a substantial increase in serum levels of ALP, ALT, and AST in nontreated animals, i.e., control (3 days and then 10 days after $\mathrm{CCl}_{4}$ injection). On the other side, the pretreated animals with the two tested doses respectively revealed a great decrease in the previously mentioned enzymes.
Serum ALP, ALT, and AST levels in rats treated with the dose of $200 \mathrm{mg} / \mathrm{kg}$ b. wt. were $(24.2,21.2 \mathrm{KAU})$, $(61.3,51.9 \mathrm{u} / \mathrm{l})$, and $(65.9,53.9 \mathrm{u} / \mathrm{l})$ after 3 days and 10 days, respectively. This significant reduction could be comparable to that of silymarin in which the serum AST, ALT, and ALP levels were $(48.2,39.2 \mathrm{u} / \mathrm{l})$ and (63.8, $39.1 \mathrm{u} / \mathrm{l})$ and $(16.8,7.9 \mathrm{KAU})$ after 3 days and 10 days, respectively (Supplementary file: Table S2-S4) (Figs. 4, 5, and 6).

\section{Discussion}

Genus Acacia belongs to the family Fabaceae. Acacia species were being used in the beginnings of civilization as traditional medicinal herbs which are of considerable medicinal and economic value. Therefore, investigation of non-flowering aerial parts of $A$. modesta cultivated in Egypt has led to the following findings: The chemical investigation of butanol fraction of A. modesta nonflowering aerial parts yielded three compounds. According to the chromatographic properties, compound 1 was expected to be apigenin derivative [17], confirmed by ${ }^{1} \mathrm{H}$ NMR spectrum and ${ }^{13} \mathrm{C}$ NMR spectrum showing typical signals of the apigenin aglycone moieties giving the confirmation of vitexin-2' '- $\beta$-glucopyranoside that has been separated for the first time from genus Acacia. In the same spectra of ${ }^{13} \mathrm{C}-\mathrm{NMR}$, another compound having signal strength close to $1: 2$ of the first compound, the aglycone moiety of the second compound seems to be

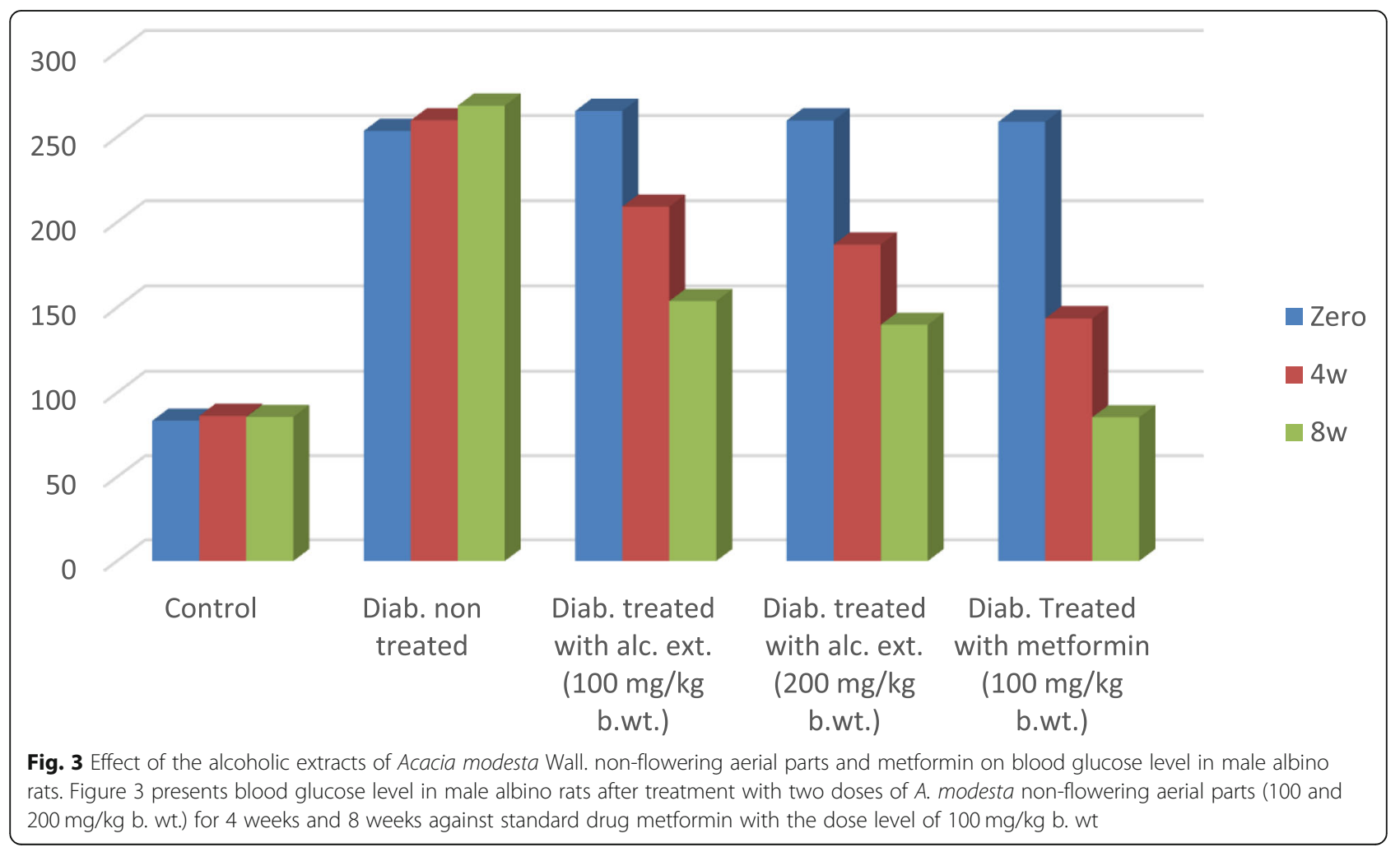




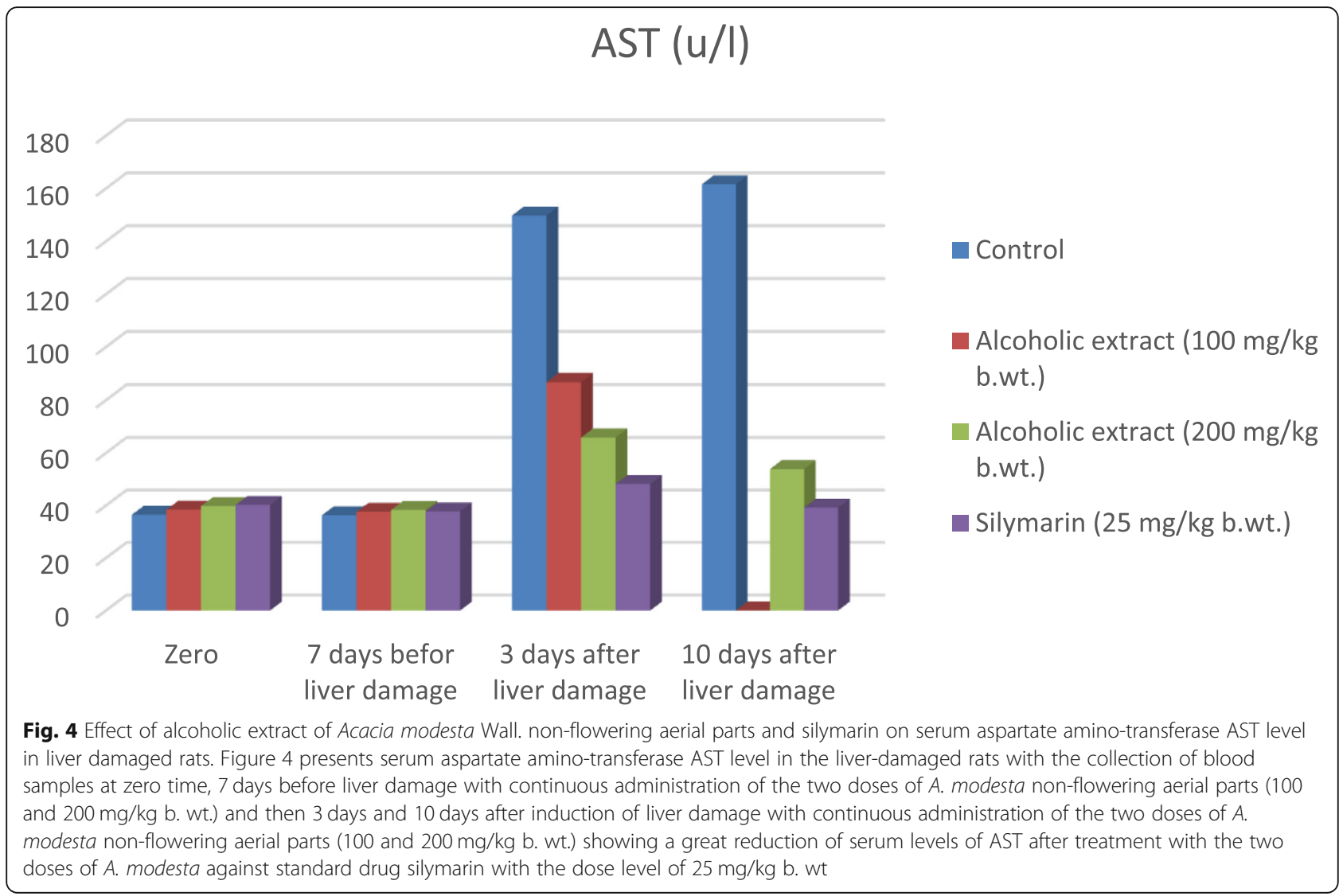

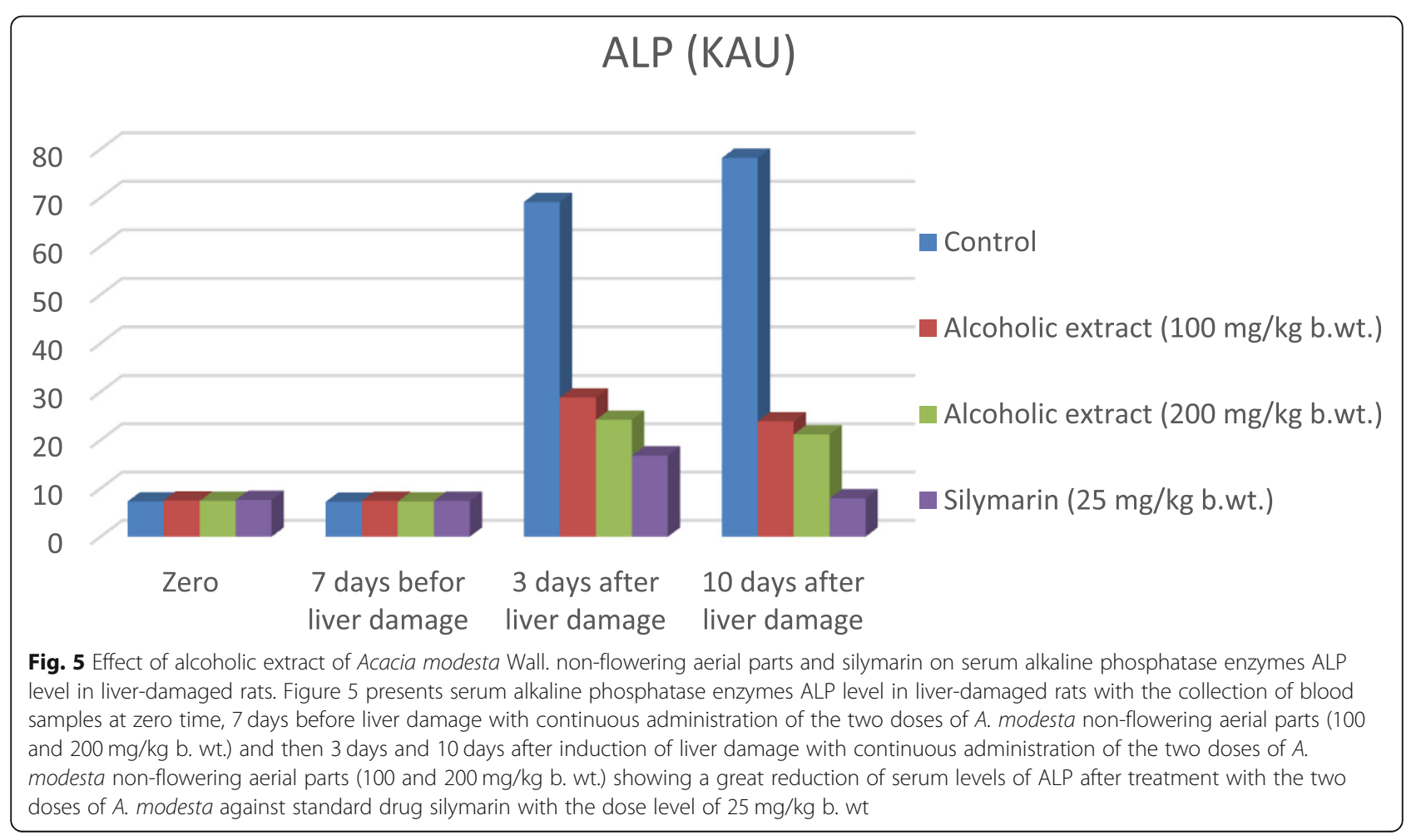




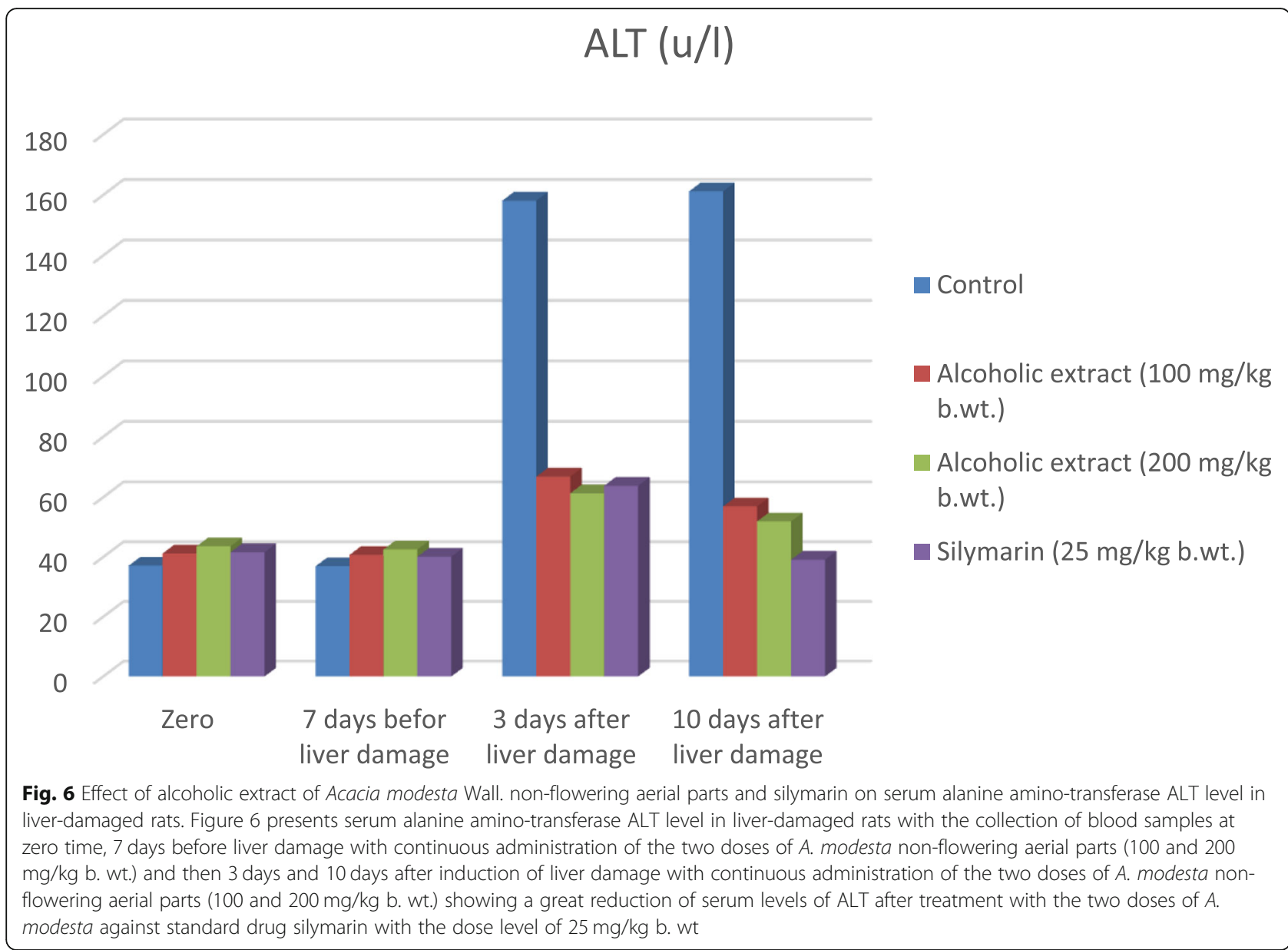

identical to the first one except in carbon number 6 of the aglycone. Comparing the chemical shift of the carbon spectra, compound 2 was confirmed to be apigenin-6,8-di- $C$ - $\beta$ - $D$-glucopyranoside (vicenin II), that was separated for the first time from genus Acacia. According to the chromatographic properties, ${ }^{1} \mathrm{H}$ and ${ }^{13} \mathrm{C}$ NMR spectrum of compound 3 revealed 30 carbon signals of the aglycone that have been sorted into nine methylenes, nine quaternary carbons, seven methyls, and six methines by DEPT experiments. This data suggested that it is a triterpene of an oleanane-type, the carbonyl function appears at $\delta 200.1$ corresponding to ketone function at $\mathrm{C}-11$. The previous data in addition to the other carbons in the spectra with the 2D-NMR experiments ( $\mathrm{H}-\mathrm{H}$ COSY, HSQC, DEPT, HMBC) came in complete accordance with the previously published data of $\beta$ - $D$-glucopyranosyl (1-3)- $\beta$ - $D$-glucopyranosyl)-3- $\beta$ hydroxy-11-oxo-olean-12-en-28-oic acid which was separated for the first time from family Fabaceae.

Eighteen compounds were tentatively identified using (UPLC-ESI-MS) analysis of the ethyl acetate fraction compared with previously published references presented in Table 1 and are discussed in the following section:
Compound $1 R T$ 0.86; it has been tentatively proposed as a caffeic acid ester derivative with $[\mathrm{M}+\mathrm{H}]^{+}$of $m / z$ $295 \mathrm{amu}$, because of showing similar peaks. The MS fragmentation shows the characteristic fragment ion of caffeic acid at $m / z 136$ (Supplementary file: Figure S16). Compound $2 R T$ 6.91; the molecular formula of this compound was found to be $\mathrm{C}_{21} \mathrm{H}_{20} \mathrm{O}_{11}$ (orientin). With the characteristic base peak at $\mathrm{m} / z 327$ (Supplementary file: Figure S17). Compound $3 R T$ 7.75; it has been tentatively identified as coumaroyl diferuoyl spermidine, with the molecular formula of $\mathrm{C}_{36} \mathrm{H}_{41} \mathrm{~N}_{3} \mathrm{O}_{8}$, with the deprotonated ion $[\mathrm{M}-\mathrm{H}]^{-}$at $m / z 642.2$ (Supplementary file: Figures S18-S19). Compound $4 R T$ 8.27; with the precursor ion peak of $[\mathrm{M}-\mathrm{H}]^{-}$at $m / z$ 626.2. It can be tentatively supposed to be quercetin dihexose, with the characteristic aglycone at $\mathrm{m} / \mathrm{z}$ 301.1, known for quercetin $[(\mathrm{M}-\mathrm{H})-2 \mathrm{Hexose}]^{-}$(Supplementary file: Figure S20). Compound 5 RT 8.48; could be tentatively assigned as apigenin-O-pentosyl hexoside with the molecular formula $\mathrm{C}_{26} \mathrm{H}_{28} \mathrm{O}_{14}$. The precursor ion peak $[\mathrm{M}+\mathrm{H}]^{+}$at $\mathrm{m} / z 565.2$ and the $[\mathrm{M}+\mathrm{Na}]^{+}$ion at $\mathrm{m} / z 587$ (Supplementary file: Figure S21). Compound $6 R T$ 8.67; it has been tentatively identified as apiin with the molecular 
Table 1 Identification of the metabolites of the ethyl acetate fraction of Acacia modesta Wall. non-flowering aerial parts

\begin{tabular}{|c|c|c|c|c|c|c|c|c|c|}
\hline No. & RT & Name & $M-H$ & $M+H$ & $\mathrm{M}+\mathrm{Na}$ & $M+K$ & Mol. formula & Fragments & Reference \\
\hline 1 & 0.86 & Caffeic acid ester derivative & & 295 & & & $\begin{array}{ll}------- \\
-4\end{array}$ & 136 & [20] \\
\hline 2 & 6.91 & Orientin & 448.2 & & & & $\mathrm{C}_{21} \mathrm{H}_{20} \mathrm{O}_{11}$ & 327.1 & [21-23] \\
\hline 3 & 7.75 & Coumaroyl diferuoyl spremidine & 642.2 & & & & $\mathrm{C}_{36} \mathrm{H}_{41} \mathrm{~N}_{3} \mathrm{O}_{8}$ & $147.1,307.1,327.1$ & [24] \\
\hline 4 & 8.27 & Quercetin dihexose & 626.2 & & & & $\mathrm{C}_{27} \mathrm{H}_{30} \mathrm{O}_{17}$ & 301.1 & {$[24,25]$} \\
\hline 5 & 8.48 & Apigenin-O-pentosyl hexoside & & 565.2 & 587.2 & & $\mathrm{C}_{26} \mathrm{H}_{28} \mathrm{O}_{14}$ & 273.2 & {$[26,27]$} \\
\hline 6 & 8.67 & Apiin & & 565.2 & 588.2 & & $\mathrm{C}_{26} \mathrm{H}_{28} \mathrm{O}_{4}$ & 433.1 & {$[28,29]$} \\
\hline 7 & 8.89 & Myricetin-rhamnose malic acid & 579.3 & & & & $\mathrm{C}_{24} \mathrm{H}_{23} \mathrm{O}_{16}$ & 316.1, 463.1 & [29] \\
\hline 8 & 9.02 & Granatin B & & 951.3 & & & $\mathrm{C}_{41} \mathrm{H}_{28} \mathrm{O}_{27}$ & 303.1, 465.1 & {$[30,31]$} \\
\hline 9 & 9.88 & Catechin trigallate & 745.3 & & & & $\mathrm{C}_{36} \mathrm{H}_{15} \mathrm{O}_{18}$ & 447.1, 593.2 & [32] \\
\hline 10 & 10.20 & Ellagic acid derivative & & 799.3 & & & -------- & 271.1, 331.1, 395.2 & [30] \\
\hline 11 & 11.80 & Kaempferol hexose glucuronide & 623.3 & & 647.1 & & $\mathrm{C}_{27} \mathrm{H}_{28} \mathrm{O}_{17}$ & 287.1 & [24] \\
\hline 12 & 22.59 & Tricaffeoyl-quinic acid & & 677.5 & & & $\mathrm{C}_{34} \mathrm{H}_{30} \mathrm{O}_{15}$ & $\mathbf{3 5 1 . 2}, 515.3$ & [33] \\
\hline 13 & 22.84 & Pentagalloyl hexoside & & 993.2 & & & $\mathrm{C}_{41} \mathrm{H}_{32} \mathrm{O}_{26}$ & 496.4 & [34] \\
\hline 14 & 23.46 & Quercetin hexose glucuronide & & 641.2 & & & $\mathrm{C}_{27} \mathrm{H}_{28} \mathrm{O}_{18}$ & 304.3, & [24] \\
\hline 15 & 23.69 & Digalloyl hexose & & & 507.7 & 524.7 & $\mathrm{C}_{20} \mathrm{H}_{20} \mathrm{O}_{14}$ & $313.4,331.3$ & [35] \\
\hline 16 & 24.35 & Quercetin-tri-O-hexoside & & & & 827.7 & $\mathrm{C}_{33} \mathrm{H}_{39} \mathrm{O}_{21}$ & 303.1, 624.3 & [20] \\
\hline 17 & 24.49 & Galloyl-valoneic acid bilactone & & 623.2 & & & -------- & 469.4 & {$[29,30]$} \\
\hline 18 & 27.56 & 7-O-Methyl- delphinidin-3-O-(2"galloyl)-hexoside & & 631.1 & & & $\mathrm{C}_{29} \mathrm{H}_{26} \mathrm{O}_{16}$ & $153.1,235$ & [29] \\
\hline
\end{tabular}

$M+H^{+}$protonated molecular ion; $M-H$ - deprotonated molecular ion; $\mathrm{m} / \mathrm{z}$ mass to charge; $M+K$ protonated/deprotonated, $\mathrm{K}^{+}$adduct; $M+N a$ protonated/ deprotonated, $\mathrm{Na}^{+}$adduct; $\mathrm{Mol}$. formula molecular formula; $R T$ retention time

formula $\mathrm{C}_{26} \mathrm{H}_{28} \mathrm{O}_{4}$ and $[\mathrm{M}+\mathrm{H}]^{+}$peak at $m / z 565.2$ with a molecular weight 564 with the characteristic base peak ion at $m / z 433$ due to the loss of a pentose unit [(M + $\left.\mathrm{H})^{+}-132\right]^{+}$and the $[\mathrm{M}+\mathrm{Na}]^{+}$ion at $\mathrm{m} / z 588.2$ (Supplementary file: Figure S22). Compound 7 RT 8.89; it has been tentatively identified as myricetin-rhamnose malic acid was detected in -ve ESI mode showing a precursor ion peak at $\mathrm{m} / z 579$ having the molecular formula $\mathrm{C}_{27} \mathrm{H}_{30} \mathrm{O}_{13}$. The base peak ion at $m / z 463.1$ appeared due to the removal of malic acid $[(\mathrm{M}-\mathrm{H})-116]^{-}$at $m /$ $z 579$ to give a myricetin-rhamnose moiety. A characteristic fragment of the aglycone myricetin appeared at $\mathrm{m} / \mathrm{z}$ 316 , also the $[(\mathrm{M}-\mathrm{H})+\mathrm{K}]^{-}$ion at $m / z$ 609. (Supplementary file: Figure S23). Compound $8 R T$ 9.02; exhibited a precursor ion at $\mathrm{m} / \mathrm{z} 951.3$ which is assigned for granatin B; (Galloyl-hexahydroxydiphenoyl-di-hexahydroxydiphenoyl-hexoside), hexa-hydroxy-diphenoyl (dehydro-ellagitannins of type III-tannins) (Supplementary file: Figure S24). Compound 9 RT 9.88; it is tentatively assigned as catechin trigallate with the precursor ion peak $[\mathrm{M}-$ $\mathrm{H}]^{-}$at $m / z 745.3$, showing a minor production $[(\mathrm{M}-\mathrm{H})-$ $152]^{-}$at $m / z 593.2$ due to removal of a gallic acid unit (Supplementary file: Figure S25). Compound 10 RT 10.20 is tentatively assigned as ellagic acid derivative showing a precursor ion at $m / z 799.3$ and the base peak ion at $m / z$ 271.1 (Supplementary file: Figure S26). Compound $11 R T$ 11.80; with the molecular formula $\mathrm{C}_{27} \mathrm{H}_{28} \mathrm{O}_{17}$ and molecular weight 624 , it can be recognized as kaempferol hexose glucuronide with a precursor ion peak $[\mathrm{M}-\mathrm{H}]^{-}$at $m / z$ 623.3 and the base peak ion fragment $[(\mathrm{M}+\mathrm{H})$-hexoseGlucuronide] ${ }^{+}$at $m / z 287.1$ (Supplementary file: Figure S27-S28). Compound 12 RT 22.59; it has been tentatively identified as tricaffeoyl-quinic acid with the base peak ion at $m / z 515$ (Supplementary file: Figure S29). Compound $13 R T$ 22.84; it has been assigned as pentagalloyl hexoside as a hydrolysable tannin with $[\mathrm{M}+\mathrm{H}]^{+}$ion peak at $m / z$ 993 and the base peak ion at $m / z$ 496.4 (Supplementary file: Figure S30). Compound 14 RT 23.46; with the molecular formula of $\mathrm{C}_{27} \mathrm{H}_{28} \mathrm{O}_{18}$ and molecular weight 640 and the precursor ion peak $[\mathrm{M}+\mathrm{H}]^{+}$at $m / z 641.2$, it can be recognized tentatively as quercetin hexose glucuronide (Supplementary file: Figure S31). Compound 15 RT 23.69; it has been tentatively identified as an isomer of digalloyl hexose with the ion peak of $[\mathrm{M}+\mathrm{Na}]^{+}$at $m / z 507.7$ and the $[\mathrm{M}+\mathrm{K}]^{+}$ion at $m / z 524.7$ (Supplementary file: Figure S32). Compound $16 R T$ 24.35; it has been assigned as quercetin-tri-O-hexoside with the precursor ion peak $[\mathrm{M}$ $+\mathrm{K}]^{+}$at $m / z 827.7$ and the base peak ion at $m / z 303.1$ corresponding to the aglycone quercetin (Supplementary file: Figure S33). Compound 17 RT 24.49 exhibited a precursor ion peak at $\mathrm{m} / \mathrm{z} 623.2$ and also an observance of galloyl moiety removal $[(\mathrm{M}-\mathrm{H})-152]^{-} \mathrm{m} / z$ 469.4. Thus, this compound was tentatively identified as galloyl-valoneic acid bilactone (Supplementary file: Figure S34). Compound $18 R T 27.56$ has been assigned as 7-O-methyl-delphinidin-3-O-(2' galloyl)-hexoside with the precursor 
fragment at $m / z 631.1$ and characteristic ions of $\mathrm{m} / \mathrm{z} 153$ $[(\mathrm{M}+\mathrm{H}) \text {-delphinidin-hexose }]^{+}$due to loss of delphinidin and hexose moieties (Supplementary file: Figure S35).

Eventually, the ethanol extract of $A$. modesta Stocks of the two tested doses of $100 \mathrm{mg} / \mathrm{kg} \mathrm{b}$. wt. and $200 \mathrm{mg} / \mathrm{kg}$ b. wt. decreased the blood sugar level of AITD after 4 weeks by $21.1 \%$ and $28 \%$, respectively, when compared to the reference drug metformin (44.5\%). Also, the ethanol extract of $A$. modesta Stocks decreased the blood sugar level of AITD after 8 weeks by $42.1 \%$ and $46.1 \%$ in the two tested doses, respectively, when compared to the reference drug metformin (67\%). It can be concluded that the most potent extracts were A. modesta $(200 \mathrm{mg} /$ $\mathrm{kg}$ b. wt.) followed by $A$. modesta $(100 \mathrm{mg} / \mathrm{kg}$ b. wt.) after 4 weeks and 8 weeks with a potency $62.9 \%$ and $68.8 \%$ and a potency $47.6 \%$ and $62.8 \%$, respectively, compared to metformin ( $100 \mathrm{mg} / \mathrm{kg}$ b. wt.) which is considered $100 \%$ potent. It is important to mention that levels of blood glucose were tested in normal and AITD, given ethanol and ethanol: water (1:1) leaf extracts of $A$. modesta cultivated in India, at two dose levels of 100 and $300 \mathrm{mg} / \mathrm{kg} / \mathrm{day}$ [36]. Nevertheless, this is the first report for the anti-diabetic activity of the plant cultivated in Egypt. Regarding the hepato-protective activity, a remarkable reduction in the levels of serum enzymes was observed. After treatment with the two doses of $100 \mathrm{mg} /$ $\mathrm{kg}$ b. wt. and $200 \mathrm{mg} / \mathrm{kg}$ b. wt., respectively; the percent of reduction were found to be $42.1 \%, 56 \%$ for AST; $57.7 \%, 61.2 \%$ for ALT; and $58.3 \%, 65 \%$ for ALP compared with the reference drug silymarin $67.8 \%, 59.6 \%$, and $75.7 \%$ for AST, ALT, and ALP, respectively, after 3 days. While after 10 days, percent of reduction was found to be $(53.7 \%, 66 \%$ for AST and $64.7 \%, 67.8 \%$ for ALT and $69.4 \%$, 73\% for ALP compared with the reference drug silymarin $75.7 \%, 75.7 \%$, and $90 \%$ for AST, ALT, and ALP after treatment with the two tested doses, respectively. It could be concluded that the most potent extract was that of dose level $200 \mathrm{mg} / \mathrm{kg} \mathrm{b}$. wt. with percent of potency $(82.6 \%, 102.7 \%$, and $85.9 \%)$ for AST, ALT, and ALP, respectively, after 3 days of treatment. While the percent of potency was found to be $(88 \%, 89.6 \%$, and $81.1 \%)$ for AST, ALT, and ALP, respectively, after 10 days of treatment compared to the standard drug silymarin (which is considered $100 \%$ potent). It is important to mention that the hepato-protective activity of the stem bark of $A$. modesta was previously investigated using $80 \%$ methanolic extract of the Pakistanian cultivated species crude extract [37]. This is the first report for the hepatoprotective activity of $A$. modesta cultivated in Egypt.

\section{Conclusion}

Acacia modesta Wall. cultivated in Egypt revealed the presence of a variety of phytochemical constituents and showed low toxicity profiles with high safety margins and valuable hypoglycemic, hepato-protective activities. This superior activity would be attributed to their high contents of phenolic components and flavonoids. Further investigation is recommended on the total extracts and individual components. Clinical trials should be performed in order to support the above investigation and to facilitate their pharmaceutical formulation.

\section{Supplementary Information}

The online version contains supplementary material available at https://doi. org/10.1186/s43094-020-00134-x.

\begin{abstract}
Additional file 1: Figure S1. ${ }^{1} \mathrm{H}-\mathrm{NMR}$ spectral data of the flavone mixture (400 MHz, CD3OD). Figure S2. ${ }^{13} \mathrm{C}-\mathrm{NMR}$ total carbons spectral data of the flavone mixture (100 MHz, CD3OD). Figure S3. ${ }^{13} \mathrm{C}-\mathrm{NMR}$ total carbons spectral data of the flavone mixture (100 MHz, CD3OD). Figure S4. HMBC-DEPT 90 spectral data of the flavone mixture (CD3OD). Figure S5. HMBC-DEPT 135 spectral data of the flavone mixture (CD3OD). Figure S6. HSQC-DEPT 90 spectral data of the flavone mixture (CD3OD). Figure S7. HSQC-DEPT 135 spectral data of the flavone mixture (CD3OD). Figure S8. ${ }^{1} \mathrm{H}-\mathrm{NMR}$ spectral data of compound three $(400 \mathrm{MHz}, \mathrm{CD} 3 \mathrm{OD})$. Figure S9. ${ }^{13} \mathrm{C}-\mathrm{NMR}$ DEPT 90 spectral data of compound three (100 $\mathrm{MHz}, \mathrm{CD} 3 \mathrm{OD}$ ). Figure S10. ${ }^{13} \mathrm{C}-\mathrm{NMR}$ DEPT 135 spectral data of compound three (100 MHz, CD3OD). Figure S11. HMBC-DEPT 90 spectral data of compound three (CD3OD). Figure S12. HMBC-DEPT 135 spectral data of compound three (CD3OD). Figure S13. HSQC-DEPT 90 spectral data of compound three (CD3OD). Figure S14. HSQC-DEPT 135 spectral data of compound three (CD3OD). Figure S15. $\mathrm{H}-\mathrm{H}$ Cosy spectral data of compound three (CD3OD)
\end{abstract}

\section{Abbreviations}

ALP: Alkaline phosphatase; ALT: Alanine amino-transferase; AST: Aspartate amino-transferase; UPLC-ESI-MS: Ultra-performance liquid chromatographyelectrospray ionization - mass spectrometry; +ve ESI: Positive mode of electrospray ionization; A. modesta: Acacia modesta; AITD: Alloxan-induced type 2 diabetic rats; b. wt.: Body weight; BEH C-18: Ethylene-bridged hybrid carbon 18 reversed-phase; $\mathrm{CCl}_{4}$ : Carbon tetrachloride; DEPT: Distortion-less enhancement by polarization transfer; -ve ESI: Negative mode of electrospray ionization; ext.: Extract; $\mathrm{H}-\mathrm{H}$ cosy: Proton-proton correlation spectroscopy; HMBC: Hetero-nuclear multiple quantum coherence;

HSQC: Hetero-nuclear single quantum coherence; LD $D_{50}$ : Median lethal dose; Rf. Retention factor; RP: Reversed-phase; RT: Retention time; TLC: Thin layer chromatography

\section{Acknowledgements}

The authors are thankful to prof. Amany Sleem professor of Pharmacology, Department of Pharmacology, National Research Centre, Dokky, Giza, Egypt, who carried out the experimental activities in the pharmacology section.

\section{Authors' contributions}

EMS is a research scholar who carried out the practical work, data collection, data interpretation, and analysis and was a major contributor in writing the manuscript. MHG is a professor in Pharmacognosy who designed the work and helped in data interpretation and analysis and critical revision of the article. RRI is a lecturer in Pharmacognosy who helped in practical work and data collection. HSMS is a professor in Pharmacognosy who revised the article and gave the final approval of the manuscript to be published. The authors read and approved the final manuscript.

\section{Funding}

This research did not receive any specific grant from funding agencies in the public, commercial, or not-for-profit sectors.

Availability of data and materials

Data and materials are available upon request. 


\section{Ethics approval and consent to participate}

Experiments and animal procedures have been carried out in compliance with the Ethics Committee of the National Research Centre following the recommendations of the National Institutes of Health Guide for care and use of laboratory animals and approved by the Ethical Committee of Faculty of Pharmacy, Helwan University, Ain-Helwan, Cairo, Egypt, of the protocol numbered (008A-16).

\section{Consent for publication}

Not applicable.

\section{Competing interests}

The authors declare that they have no competing interests.

\section{Author details}

${ }^{1}$ Faculty of Pharmaceutical Sciences and Pharmaceutical Industries, Future University in Egypt, Cairo, Egypt. ${ }^{2}$ Faculty of Pharmacy, Pharmacognosy Department, Helwan University, P.O. Box 11795, Ain-Helwan, Cairo, Egypt.

\section{Received: 2 May 2020 Accepted: 6 August 2020}

\section{Published online: 14 December 2020}

\section{References}

1. Ayyanar M, Silambarasan R (2015) An ethnobotanical study of medicinal plants in Palamalai region of eastern Ghats. India. J Ethnopharmacol 172:162-178

2. Ahmad F, Anwar F, Hira S (2016) Review on medicinal importance of Fabaceae family. Pharmacol Online 3:151-156

3. Or K, Ward D (2003) Three-way interactions between Acacia, large mammalian herbivores and bruchid beetles. Afr J Ecol 41:257-265

4. Subhan N (2016) Phytochemical and pharmacological investigations of Australian Acacia: an ethnomedicine-guided bioprospective approach. Charles Sturt University, Dhaka, Bangladesh, p 317 Available from: https:// researchoutput.csu.edu.au/en/publications/phytochemical-andpharmacological-investigations-of-australian-ac-3

5. Bukhari IA, Khan RA, Gilani AH, Sagheer A, Arshad SS (2010) Analgesic, antiinflammatory and anti-platelet activities of the methanolic extract of Acacia modesta leaves. Inflammopharmacology 18:187-196

6. Sarwar W (2016) Pharmacological and phytochemical studies on Acacia modesta wall; a review. JPHYTO 5:160-166

7. Kalita P, Tapan B, Pal T, Kalita R (2013) Estimation of total flavonoids content (TFC) and antioxidant activities of methanolic whole plant extract of Biophytum sensitivum Linn. JDDT 3:33-37. https://doi.org/10.22270/jddt.v3i4. 546 Available from: http://jddtonline.info/index.php/jddt/article/view/546

8. Osama S, El Sherei M, Al-Mahdy DA, Bishr M, Salama O (2019) Effect of salicylic acid foliar spraying on growth parameters, $y$-pyrones, phenolic content and radical scavenging activity of drought stressed Ammi visnaga $\mathrm{L}$. plant. Ind Crop Prod 134:1-10. https://doi.org/10.1016/j.indcrop.2019.03.035

9. Kärber G (1931) Beitrag zur kollektiven Behandlung pharmakologischer Reihenversuche. Archiv f Exper Pathol u Pharmakol 162:480-483. https://doi. org/10.1007/BF01863914

10. Eliasson SG, Samet TM (1969) Alloxan induced neuropathies lipid changes in nerve and root fragments. Life Sci 8:493-498

11. Trinder $P$ (1969) Determination of glucose in blood using glucose oxidase with an alternative oxygen acceptor. Ann Clin Biochem:6-24 Available from: https://journals.sagepub.com/doi/abs/10.1177/000456326900600108

12. Klassen CD, Plaa GL (1969) Comparison of the biochemical alteration elicted in liver of rats treated with carbon tetrachloride, chloroform 1,1,2trichloroethane and 1,1,1-trichloroethane. Biochem Pharmacol 18:2019-2022

13. El-Askary HI, El-Olemy MM, Salama MM, Amer MH (2013) Development and validation of a high-performance liquid chromatography method for standardization of the bioactive ethyl acetate fraction of Alstonia scholaris (Linn.) R. Br. Growing in Egypt. Z Naturforsch C J Biosci 68:376-383

14. Thewfweld W (1974) The enzymatic methods for determination of serum AST and ALT. Deutsch Med 99:343-347

15. Kind PR, King EG (1954) A colorimetric method for the determination of serum alkaline phosphatase. J Clin Pathol 7:322

16. Snedecor GW, Cochran WG (1971) Méthodes Statistiques, original title: statistical methods, 6th edn. lowa State University Press, Ames, p 649

17. Mabry TJ, Markham KR, Thomas MB (1970) The systematic identification of flavonoids. Springer- Verlag, New York, p 354
18. Xiong Q, Wilson WK, Pang J (2007) The Liebermann-Burchard reaction: sulfonation, desaturation, and rearrangement of cholesterol in acid. Lipids 42:87-96

19. Buck WB, Osweiler GD, Van Gelder GA (1976) lodine in clinical and diagnostic veterinary toxicology, 2nd edn. Kendall/Hunt, Dubuque, pp 69-75

20. Francescato LN, Debenedetti SL, Schwanz TG, Bassani VL, Henriques AT (2013) Identification of phenolic compounds in Equisetum giganteum by LC-ESI-MS/ MS and a new approach to total flavonoid quantification. Talanta 105:192-203

21. Krasteva I, Nikolov S (2008) Flavonoids in Astragalus corniculatus. Quim Nova 31:59-60

22. Pereira OR, Silva AMS, Domingues MRM, Cardoso SM (2012) Identification of phenolic constituents of Cytisus multiflorus. Food Chem 131:652-659

23. Brito A, Ramirez JE, Areche C, Sepúlveda B, Simirgiotis MJ (2014) HPLC-UVMS profiles of phenolic compounds and antioxidant activity of fruits from three citrus species consumed in northern Chile. Molecules 19:17400-17421

24. Hanhineva K, Rogachev I, Kokko H, Mintz-Oron S, Venger I, Kärenlampi S, Aharoni A (2008) Non-targeted analysis of spatial metabolite composition in strawberry (Fragaria $\times$ ananassa) flowers. Phytochemistry 69:2463-2481

25. Truchado P, Vit P, Heard TA, Tomás-Barberán FA, Ferreres F (2015) Determination of interglycosidic linkages in O-glycosyl flavones by high-performance liquid chromatography/photodiode-array detection coupled to electrospray ionization ion trap mass spectrometry. Its application to Tetragonula carbonaria honey from Australia. Rapid Commun Mass Spectrom 29:948-954

26. Wojakowska A, Muth D, Narozna D, Madrzak C, Stobiecki M, Kachlicki P (2013) Changes of phenolic secondary metabolite profiles in the reaction of narrow leaf lupin (Lupinus angustifolius) plants to infections with Colletotrichum lupini fungus or treatment with its toxin. Metabolomics 9:575-589

27. Wojakowska A, Piasecka A, García-López PM, Zamora-Natera F, Krajewski P, Marczak L, Kachlicki P, Stobiecki M (2013) Structural analysis and profiling of phenolic secondary metabolites of Mexican lupine species using LC-MS techniques. Phytochemistry 92:71-86

28. Blunder M, Orthaber A, Bauer R, Bucar F, Kunert O (2017) Efficient identification of flavones, flavanones and their glycosides in routine analysis via off-line combination of sensitive NMR and HPLC experiments. Food Chem 218:600-609

29. Abu-Reidah IM, Ali-Shtayeh MS, Jamous RM, Arráez-Román D, SeguraCarretero A (2015) HPLC-DAD-ESI-MS/MS screening of bioactive components from Rhus coriaria L. (sumac) fruits. Food Chem 166:179-191

30. Fischer UA, Carle R, Kammerer DR (2011) Identification and quantification of phenolic compounds from pomegranate (Punica granatum L.) peel, mesocarp, aril and differently produced juices by HPLC-DAD-ESI/MS ${ }^{n}$. Food Chem 127:807-821

31. Mena P, Calani L, Dall'Asta C, Galaverna G, García-Viguera C, Bruni R, Crozier A, Del-Rio D (2012) Rapid and comprehensive evaluation of (poly)-phenolic compounds in pomegranate (Punica granatum L.) juice by UHPLC-MS ${ }^{n}$. Molecules 17:14821-14840

32. Maldini M, Montoro P, Hamed Al, Mahalel UA, Oleszek W, Stochmal A, Piacente S (2011) Strong antioxidant phenolics from Acacia nilotica: profiling by ESI-MS and qualitative-quantitative determination by LC-ESI-MS. J Pharm Biomed Anal 56:228-239

33. Llorent-Martínez EJ, Zengin G, Fernández-de Córdova ML, Bender O, Atalay A, Ceylan R, Mollica A, Mocan A, Uysal S, Guler GO, Aktumsek A (2017) Traditionally used lathyrus species: phytochemical composition, antioxidant activity, enzyme inhibitory properties, cytotoxic effects, and in silico studies of Lathyrus czeczottianus and Lathyrus nissolia. Front Pharmacol 8:1-20

34. Sobeh M, El-Hawary E, Peixoto H, Labib RM, Handoussa H, Swilam N, ElKhatib AA, Sharapov F, Mohamed T, Krstin S, Linscheid MW, Singab AN, Wink M, Ayoub N (2016) Identification of phenolic secondary metabolites from Schotia brachypetala Sond. (Fabaceae) and demonstration of their antioxidant activities in Caenorhabditis elegans. Peer J 4:e2404

35. Lee JH, Johnson JV, Talcott ST (2005) Identification of ellagic acid conjugates and other polyphenolics in muscadine grapes by HPLC-ESI-MS. J Agric Food Chem 53:6003-6010

36. Jawla S, Kumar Y, Khan MSY (2011) Antimicrobial and anti-hyperglycemic activities of Acacia modesta leaves. Pharmacologyonline 2:331-347 Available from: https://pharmacologyonline.silae.it/files/archives/2011/vol2/036.kumar.pdf

37. Rahaman M, Chaudhry M (2015) Evaluation of antioxidant and hepatoprotective effect of Acacia modesta wall. Against paracetamol induced hepatotoxicity. BJPR 5:336-343

\section{Publisher's Note}

Springer Nature remains neutral with regard to jurisdictional claims in published maps and institutional affiliations. 